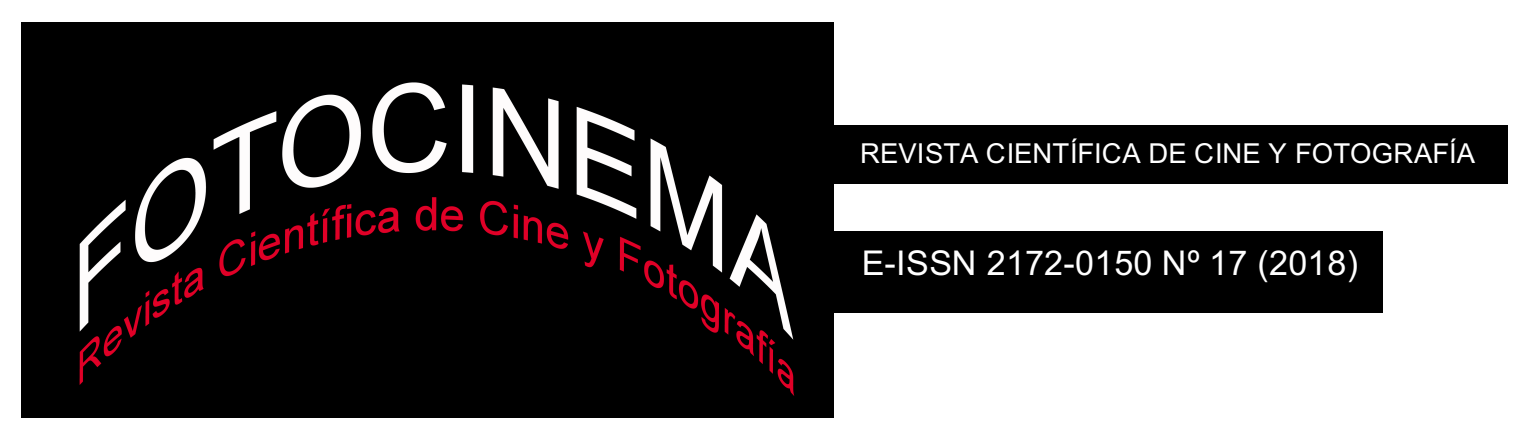

Higueras Flores, Rubén y Rodríguez Serrano, Aarón (2018). La escritura (in)visible. 50 películas esenciales para estudiar el cine clásico. Barcelona: Editorial UOC. 204 pp. Reseña de José María Galindo Pérez.

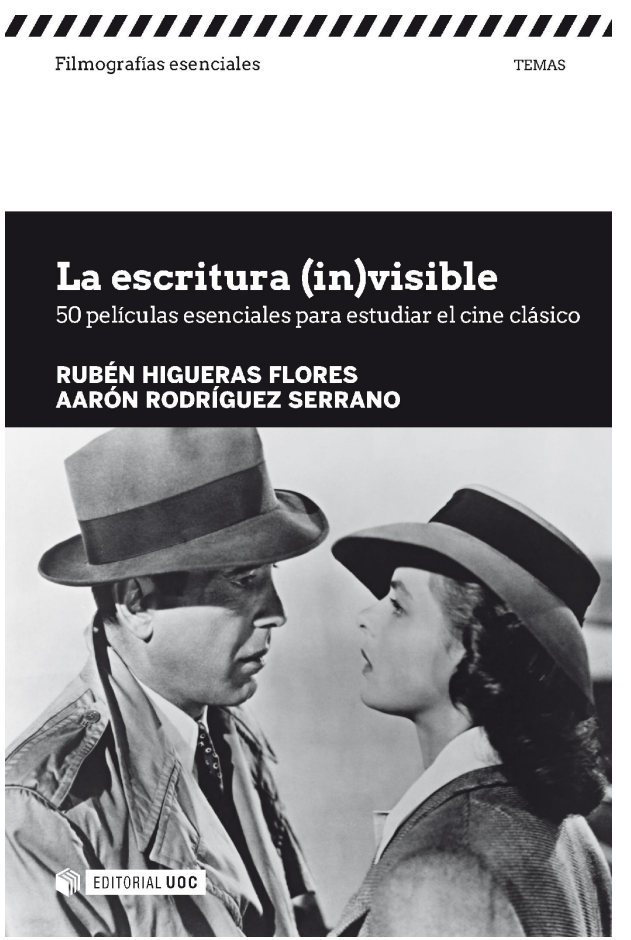

Tras una apariencia sencilla, el libro escrito por Higueras Flores y Rodríguez Serrano, dentro del marco de la colección "Filmografías esenciales", auspiciada por la editorial UOC, interpela de dos maneras al lector. La primera, a través de la propia lista de películas escogidas en el territorio del cine clásico. La segunda, mediante la colisión entre los conceptos de corpus y canon. Y, dada la trayectoria como analistas de ambos autores, el diálogo propuesto es francamente enjundioso.

Con respecto a la lista de películas, hay que tener en cuenta que, como toda lista de estas características, es una selección. Y, como toda selección de esta naturaleza, su validez radica en los criterios esgrimidos. En ese sentido, la validez está ampliamente contrastada: los análisis de cada una de las cincuenta películas, concisos pero en absoluto magros en ideas, ponen de manifiesto las numerosas aristas estéticas, económicas, sociales e ideológicas que perfilan el concepto de cine clásico. En una maniobra epistemológica similar a la ensayada en la fundamental Antología crítica del cine español (1997) editada por Julio Pérez Perucha, los autores construyen una suerte de historia del cine clásico a partir de sus manifestaciones más significativas: las películas. 
El abordaje de esas obras se realiza, evitando todo tipo de ambición holística, aprovechando las singularidades y rugosidades de cada una de ellas para discutir diversos aspectos del cine clásico: desde cuestiones de estructura narrativa hasta variaciones sobre la puesta en escena, pasando por la tarea de los intérpretes, la importancia de determinadas coyunturas históricas, la dimensión psicosociológica del espectador o el uso de las adscripciones genéricas. Esta amalgama de puntos de vista y perspectivas, lejos de dispersar o diluir el hilo conceptual fundamental sobre el cine clásico, lo refuerza. Pero lo robustece desde la particular posición historiográfica y teórica de Higueras Flores y Rodríguez Serrano: el cine clásico no es, ni puede ser, un objeto monolítico y diáfano. Por el contrario, se trata de un fenómeno poliédrico, polifónico y que se apoya en una fuerte heterogeneidad (de toda índole), y así es como los autores lo presentan y perfilan. Un método de trabajo que contribuye a enriquecer y densificar un debate que, en ocasiones, abraza con demasiada fuerza la naturalidad de una forma de hacer cine que tiene mucho más de mito que de conclusión analítica.

Siendo la selección y el comentario de las películas muy pertinentes, este libro trasciende la inicial misión y estructura de la colección editorial en la que se encuadra, alzando el vuelo al proponer al lector una segunda cuestión: el choque entre el corpus del cine clásico y el canon de dicho cine. La escritura (in)visible no puede considerarse, por lo tanto, como una sencilla y atinada agrupación de breves comentarios, sino un objeto que pone de manifiesto en todo su esplendor una fricción teórica e historiográfica muy interesante en el campo de los estudios fílmicos.

Higueras Flores y Rodríguez Serrano inician su obra con una pequeña introducción sobre lo que ellos denominan la "escritura clásica", donde esbozan el fundamento de todo un corpus fílmico. En otras palabras: repasando rasgos formales, narrativos, modelos industriales y comerciales, aspectos ideológicos (y aparatos censores) e, incluso, la posterior deriva manierista, los autores trazan las líneas maestras para identificar las películas vinculadas al cine clásico. Y lo hacen apoyándose en textos ya "clásicos" sobre el tema (perdón por el juego de palabras), como el estudio de Bordwell, Staiger y Thompson (1997), o el ensayo de Burch (1991). 
Sin embargo, el hecho de escoger cincuenta películas concretas supone plantear un canon, que no deja de ser un fragmento dentro de ese todo que constituye el corpus. El canon, además, se compone en gran medida por películas que fuerzan o tensan con mayor o menor intensidad las normas que servían para caracterizar el corpus clásico. Esta cada vez menos soterrada discrepancia desemboca en la pregunta nuclear: ¿se debe construir la historia del cine mediante las líneas de fuerza mayoritarias (el corpus) o a través de los hitos más significativos (el canon)?

A riesgo de desbordar los límites de una reseña, cabe señalar que la tensión que late bajo la aparente sencillez de una lista comentada de películas revela una confrontación entre dos linajes conceptuales y metodológicos, que tradicionalmente han mantenido unas relaciones de cierta aspereza. Por un lado, la consideración de la historia (del cine) como el registro de todo lo acontecido (lo bueno y lo malo, lo culto y lo popular, lo nuclear y lo marginal). Por otro lado, la concepción de la historia (del cine) como la selección de lo que merece ser conservado y transmitido (las cumbres estéticas y éticas). Entre esos polos, quizá quepa algún intersticio en el que el fenómeno cinematográfico se construya historiográficamente a partir de un ramillete de películas que, funcionando necesariamente como un canon, eluda las connotaciones de exclusividad artística o moralizante tantas veces asociadas al término.

Aunque los autores no comentan explícitamente esta discusión, sí parecen posicionarse en ella (aprovechando, precisamente, ese intersticio señalado), toda vez que la configuración que hacen del concepto de cine clásico se sustenta, precisamente, en la selección de películas que realizan, y, más concretamente, en las razones que les llevan a escoger esas mismas obras. ¿Se resuelve de esa forma el debate subyacente? De ninguna manera, pero tampoco era la pretensión de los autores. Su misión expresa la cumplen airosamente (algo esperable, si se atiende al elevado nivel de trabajos anteriores de los autores), y, al mismo tiempo, elaboran un material de singular valía para el debate historiográfico sobre el cine. La profundidad de ese debate, y el calado de muchas de las ideas vertidas a cuenta de las películas comentadas (muchas de ellas ampliamente visitadas por críticos y analistas, lo que dota de mucho mayor mérito a la calidad y originalidad de las 
observaciones) hacen de esta obra un referente muy valioso a la hora de, como reza el subtítulo del libro, estudiar el cine clásico.

\section{Refencias bibliográficas}

Bordwell, D., Staiger, J., Thompson, K. (1997). El cine clásico de Hollywood. Estilo cinematográfico y modo de producción hasta 1960. Barcelona: Paidós.

Burch, N. (1991). El tragaluz del infinito. Contribución a la genealogía del lenguaje cinematográfico. Madrid: Cátedra.

Pérez Perucha, J. (ed.) (1997). Antología crítica del cine español, 1906-1995: flor en la sombra. Madrid: Cátedra, Filmoteca Española y Asociación Española de Historiadores del Cine. 